\title{
COSMOLOGICAL ARGUMENT: A PRAGMATIC DEFENSE
}

\author{
EVAN SANDSMARK \& JASON L. MEGILL \\ University of Colorado • Old Dominion University
}

\begin{abstract}
We formulate a sort of "generic" Cosmological argument, i.e., a Cosmological argument that shares premises (e.g., "contingent, concretely existing entities have a cause") with numerous versions of the argument. We then defend each of the premises by offering pragmatic arguments for them. We show that an endorsement of each premise will lead to an increase in expected utility; so in the absence of strong evidence that the premises are false, it is rational to endorse them. Therefore, it is rational to endorse the Cosmological argument, and so rational to endorse theism. We then consider possible objections.
\end{abstract}

\section{INTRODUCTION}

Cosmological arguments claim that a special being of some sort (e.g., a first cause, a necessary cause, an unmoved mover, etc.) must exist to explain or account for the existence of the universe; it is then claimed that this special being is God. Such arguments have a venerable history. The first cosmological argument occurs in Plato's Laws. ${ }^{1}$ Aristotle, along with various Islamic theologians, sharpened the argument before it was discussed again by Aquinas. ${ }^{2}$ The argument also received much attention during the early modern period; Leibniz and Clarke both defended it

${ }^{1}$ See Plato, The Laws of Plato, translated by T.L. Pangle (New York: Basic Books, 1980), Book X.

${ }^{2}$ See Aristotle, The Complete Works of Aristotle, volumes I and II, edited by J. Barnes (Princeton: Princeton University Press, $4^{\text {th }}$ C BCE/1984), especially Physics VIII, 4-6 and Metaphysics XII, 1-6. See also Aquinas, Summa Theologica, translated by the Fathers of the English Dominican Republic (New York, NY: Benzinger Bros, $13^{\text {th }} \mathrm{C} / 1948$ ), especially the first part, question 2 , article 3 . 
while Hume and Kant famously criticized it. ${ }^{3}$ The argument has contemporary defenders too, including Craig, Gale and Pruss, and Koons. ${ }^{4}$ We also defend the cosmological argument. In the following section, we discuss the version of the argument that we defend. As we show, there are four premises that need justification. Then, rather than focus on metaphysical or scientific considerations in favor of the premises, we attempt a different strategy. We offer a series of pragmatic arguments that show that it is at least rational to endorse the premises; if so, it is rational to endorse theism. Finally, we consider possible objections.

\section{THE ARGUMENT}

The version of the argument that we defend consists of seven steps, and can be thought of as a sort of generic Cosmological argument. The first premise is,

(1) If $x$ is a contingent, concretely existing entity, $x$ has a cause.

The second premise claims,

(2) Our universe is a contingent, concretely existing entity.

${ }^{3}$ For the history of the argument, see W. L. Craig, The Cosmological Argument from Plato to Leibniz (London: The Macmillan Press, 1980). For Leibniz on the Cosmological argument, see The Monadology, translated by George MacDonald Ross, 1714/1999. See also S. Clarke, A Demonstration of the Being and Attributes of God and Other Writings, edited by E. Vailati (Cambridge: Cambridge University Press, 1705/1998). For Hume's criticism, see Dialogues Concerning Natural Religion (Indianapolis: Hackett, 1779/1980), part IX. See also I. Kant, Critique of Pure Reason (Cambridge: Cambridge University Press, 1980/1998), especially the Transcendental Dialectic, Book II, Chapter 3, section 5.

${ }^{4}$ See W. L. Craig, The Kalām Cosmological Argument (London: The Macmillan Press, 1979) and "In Defense of the Kaläm Cosmological Argument," Faith and Philosophy 14.2 (1997): 236-247. Also see R. Gale and A. R. Pruss, "A New Cosmological Argument," Religious Studies 35 (1999): 461-476 and R. Koons, "A New Look at the Cosmological Argument," American Philosophical Quarterly 34 (1997): 171-192. Of course, the argument has many contemporary opponents as well; see, e.g., G. Oppy, Arguing about Gods (Cambridge: Cambridge University Press, 2006), chapter 3. 
By "universe," we have something like the commonsense usage in mind, i.e., the universe is the sum total of all concretely existing matter and energy. ${ }^{5}$ The next step follows from the first two with basic logic,

(3) Our universe has a cause.

Step (4) is a disjunction that has the form of excluded middle,

(4) Either the cause of our universe is itself a part of the universe or it is not a part of our universe, i.e., it is outside the universe.

Step (5) claims,

(5) The cause of our universe is not a part of our universe.

We interpret this claim in the mereological sense; the universe can be thought of as a whole, and the cause of the universe is not a part of that whole. Step (6) follows from (4) and (5) with disjunctive syllogism,

(6) The cause of our universe must be outside the universe.

Finally,

(7) This cause of our universe is "God."

The steps that need justification are (1), (2), (5) and (7). Steps (3) and (6) follow from other steps and (4) is a logical truth. We defend (1), (2), (5) and (7) in successive sections.

\section{PREMISE ONE}

We now offer a pragmatic argument for premise one. The argument attempts to show that even assuming that one is not certain of the truth of the premise, it is still rational to endorse it. As we show, accepting the first premise has more expected utility than rejecting it, so assuming

\footnotetext{
${ }^{5}$ We do not take "universe" to mean "everything that exists," as some do. Below, we argue that there is at least one thing that exists that is not a part of the universe.
} 
that it is rational to increase expected utility, it is rational to endorse the premise, at least in the absence of strong evidence that it is false.

So, suppose that it is rational to increase expected utility. Also suppose that it is generally better to have knowledge than not have it; that is, knowledge is desirable and an increase in knowledge is also an increase in utility, at least most of time. ${ }^{6}$ Given these modest assumptions, it is rational to endorse any claim that leads to an increase in knowledge and so in expected utility, at least if we do not have sufficient evidence to reject the claim. Given that (1) has lead to a vast increase in knowledge and utility insofar as it is a vital methodological assumption of science, for example, it is rational to endorse (1). ${ }^{7}$ To rephrase the argument: (1) is either true or false. And we have two options: (a) we can believe that (1) is true or (b) we can reject it. Suppose that we opt for (a). The expected utility for this option is quite high: the assumption that (1) is true has led to the discovery of countless scientific truths as well as a number of more banal though still useful truths (e.g., "eating causes my hunger to go away"), and this is a very positive outcome. Indeed, (1) is a principle that makes reality itself intelligible. ${ }^{8}$ Further, the utility will be high whether (1) is in fact true or not (if we endorse (1) but it is false, we seem to lose very little, at least when weighed against the gains of endorsing (1)). Now, suppose that we opt for (b): the assumption that (1) is false would not lead to a positive outcome; indeed, it would lead to disastrous consequences. If we reject (1), reality would become unintelligible. If we did not think in terms of cause and effect, then we might simply stop eating, we wouldn't bother looking for cures for diseases, and so on. In short, the expected utility for rejecting (1) is extremely low; we might become extinct. If it is rational to increase expected utility, then it is rational to endorse (1). ${ }^{9}$

\footnotetext{
${ }^{6}$ We say "most of the time" because there might be cases in which it is better, at least from an expected utility standpoint, to lack knowledge than have it. Quite simply, some truths might make us unhappy, so knowing them might decrease our happiness. Even so, in general, it is better to have knowledge than not have it; who will deny this?

${ }^{7}$ Science seeks to discover the causal relationships between entities; this is the goal of science. But if (1) is false, this goal is undermined; the search for causal relationships presupposes that there are causal relationships to be found.

${ }^{8}$ See R. Taylor, Metaphysics (Englewood Cliffs: Prentice-Hall, 1992).

${ }^{9}$ To be clear, the claims that this argument rests on are extremely weak and plausible: (i) the expected utility for reality being intelligible is greater than the expected utility for
} 


\section{PREMISE TWO}

Premise (2) claims that "Our universe is a contingent, concretely existing entity." Our universe does not exist necessarily; it might not have existed. This claim is prima facie plausible; many involved, including some opponents of theism, will grant that it is true. Nevertheless, the claim requires some justification. First, note that if (2) is false, then our universe exists necessarily, and so everything in our universe necessarily exists exactly as it does etc. Consider the following argument: our universe is composed of a number of entities that stand in various relationships to one another; call our universe " $u$." Now consider a universe that is different from $u$ in some random respect, no matter how minor (e.g., in this universe, Jupiter has an additional moon, but the difference can be anything); call this universe " $u^{*}$." By hypothesis, universe $u$ is not numerically identical to $u^{*}$; this obviously follows by Leibniz's law, for instance. Furthermore, $u^{*}$ is either possible or is not possible. If $u^{*}$ is not possible, then everything in our universe is necessary; if nothing, no matter how insignificant, could have been different, then the way things are in our universe is the way they must be. But if (2) is false, then $u^{*}$ is not possible (because our universe is necessary, and it is not identical to $u^{*}$ ). But then if (2) is false, everything about our universe is necessary. The denial of (2) leads to an implausible superessentialism that few would find acceptable (an exception would be Spinoza). ${ }^{10}$

So, if (2) is false, everything about our universe is necessary, and anything that happens necessarily happens, therefore the future is "closed," i.e., it is already set in stone. This would be undesirable for a number of reasons. A gloomy fatalism threatens. It's difficult to see why anyone should be praised for an accomplishment that was fated to occur. It's difficult to see how there could be moral responsibility in such a world, in which every act was already predetermined. It's also difficult to see

reality being unintelligible and (ii) it is rational to increase expected utility. These are the only claims this argument needs.

${ }^{10}$ See B. Spinoza, The Collected Works of Spinoza Vol. I, edited and translated by Edwin Curley (Princeton: Princeton University Press, 1677/1985), Book I. The denial of (2) is so implausible many will be content to accept (2) already, even without a pragmatic argument for it. 
how there could be free will. ${ }^{11}$ Intuitively, if nothing could have possibly been different than the way it is, then any "choice" that you make could not have turned out differently, so it appears that the "choice" was not really a choice at all, and so was not really free. If there is only one possible way that the universe might be, then the outcomes of all "decisions" are predestined, and so these "decisions" are not really decisions after all etc. Now, either (2) is true or false, and we can either endorse (2) or reject it. Suppose that we reject (2) and (2) happens to be true. In this scenario, we effectively deny that the future is open, even though it is. This is clearly a negative outcome, at least given the plausible assumption that we would be happier if we believe that the future is open and thereby avoid a gloomy fatalism. Suppose that we reject (2) and (2) happens to be false. In this scenario, we are correct in asserting that the future is fixed. Yet this still appears to be a negative outcome because even if the future is fixed, we would be happier believing that it is not. In short, both outcomes for a rejection of (2) have negative expected utility. Now suppose that we assert (2) and (2) is true. This is a positive outcome: the future is not fixed and we assert it. But even if we assert (2) and (2) is false, this is still a positive outcome because again, it is "better" (at least in terms of expected utility) to falsely believe that the future is open even if it is not. Given that both outcomes for the endorsement of (2) are positive and that both outcomes for the rejection of (2) are negative, there is more expected utility for the endorsement of (2), and if it is rational to increase expected utility, then it is rational to endorse (2).

\section{PREMISE FIVE}

Premise (5) claims that "the cause of our universe is not a part of the universe," in the sense that the universe can be thought of as a whole that does not contain its cause as a part.

${ }^{11}$ For more on the importance of free will, see, e.g., T. O'Conner, "Free Will," The Stanford Encyclopedia of Philosophy (Fall 2008 Edition), edited by E. N. Zalta, URL = http://plato.stanford.edu/ archives/fall2008/entries/freewill/, introduction: "Free will also appears to be a condition on desert for one's accomplishments (why sustained effort and creative work are praiseworthy); on the autonomy and dignity of persons; and on the value we accord to love and friendship..." See also R. Kane, The Significance of Free Will (New York: Oxford University Press, 1996) and R. Clarke, Libertarian Accounts of Free Will (Oxford: Oxford University Press, 2003). 
Prima facie, it might appear difficult to formulate a pragmatic argument for (5) - the claim that the cause of the universe is outside the universe - similar to the ones given for (1) and (2). The endorsement of (5), at least taken in isolation, does not seem to have positive expected utility; but it does not appear to have negative expected utility either. At first glance, the denial of (5) doesn't appear to have a negative (or positive) expected utility either. However, given (1) and (2), (5) is true. First, suppose that (1) and (2) are true and therefore the universe has a cause. Also suppose that (5) is false; so, the cause of the universe is a part of the universe. But this cannot be the case, for if the cause of the universe is a part of the universe, we still lack a cause for the universe. That is, (1) and (2) entail that the universe has a cause, but this cause cannot be a part of the universe because anything that is a part of the universe demands a cause itself along with all of the other entities that compose the universe. But then (5) follows. Also note that even if there is an infinite chain of contingent causes, this is not sufficient to defeat (5), for the infinite chain, as a whole, still needs a cause. (1) and (2) jointly entail that the universe must have a cause; an infinite causal chain of contingent causes (assuming that there is one) would just be the universe; therefore, the infinite causal chain as a whole must have cause. Of course, this issue is related to Hume's famous objection that if we can explain the parts of a whole, we can explain the whole, so we need not venture outside of the universe to find an explanation for it. ${ }^{12}$ But as Rowe claims, "When the existence of each member of a collection is explained by reference to some other member of that very same collection then it does not follow that the collection itself has an explanation." ${ }^{13}$

Second, suppose again that (1) and (2) are true, so the universe has a cause. Posit the set $S$ that consists of all of the entities in the universe. If an entity $e$ is the cause of $S$, then $e$ is the ultimate cause of everything in $S$. But if $e$ is a part of $S$, and if $e$ causes everything in $S$, then $e$ causes itself, which is incoherent. ${ }^{14}$ Some theists (e.g., Descartes) have said that God is self-caused, so there is at least one example of an entity that causes itself,

${ }^{12}$ See again, D. Hume, Dialogues Concerning Natural Religion (Indianapolis: Hackett, 1779/1980), part IX.

${ }^{13}$ W. Rowe, The Cosmological Argument (Princeton: Princeton University Press, 1975), 264.

${ }^{14}$ We are assuming that there is no backwards causation. 
but obviously the atheist cannot claim that $e$ is God. ${ }^{15}$ So, if one rejects (5), one must reject either (1) or (2), and as we just saw, this would have a negative expected utility. Given that a denial of (5) has negative expected utility, and given that the endorsement of (5) does not, then if it is rational to maximize expected utility, it is rational to endorse (5). ${ }^{16}$

\section{STEP SEVEN}

A serious problem for the cosmological argument is the presence of a "gap" between the sort of being that the argument establishes (e.g., a first cause, a necessary cause) and the classical theistic conception of God (i.e., a being that is a necessary first cause, but is also omnipotent, omniscient, omnibenevolent and so on). An opponent can claim, for example, that even assuming that a given cosmological argument is sound, all it establishes is that, e.g., a first cause exists, but perhaps this first cause is a being that is indifferent to us, or is evil or incompetent, or is simply the material that exploded in the big bang and so is not even sentient? ${ }^{17}$ This problem applies to the version of the argument we defend as well. In this section, we discuss this issue; i.e., we attempt to justify the inference from (6) to (7).

The final step can also be given a pragmatic justification. We discuss two questions, the first of which is the following: is the cause of the universe a personal or impersonal being? In other words, is this cause (a) a sentient being that, e.g., at least takes an interest in us (and so might care about how we behave and might have some sort of a plan for us and so on), or (b) is this being sentient and completely indifferent to us or is

${ }^{15}$ See R. Descartes, Meditations on First Philosophy in The Philosophical Writigs of Descartes, Volume 2, translated by J. Cottingham, R. Stoothoff, and D. Murdoch (Cambridge: Cambridge University Press, 1641/1984).

${ }^{16}$ Even if one could somehow show that the expected utility for a denial of (5), and so a denial of either (1) or (2), is positive, one would still need to show that it is greater than the expected utility of accepting either (1) or (2).

${ }^{17}$ For more on the "gap problem," see A. Pruss, "Leibnizian Cosmological Arguments," The Blackwell Companion to Natural Theology, edited by W. L. Craig and J.P. Moreland (Oxford: Blackwell Publishing, 1999). Pointing to such gaps in theistic arguments to refute them is of course an old strategy; see, e.g., Hume's Dialogues again. 
it simply a non-sentient hunk of matter etc? ${ }^{18}$ So, suppose that we assert that (a) is true, i.e., the cause is a sentient being that takes an interest in us of some sort. And suppose that we are correct. In this scenario, we gain, or at least have the potential to gain, quite a bit. For example, if the cause of the universe cares about what we do, or has a plan of some sort for us, then our beliefs or actions might have some higher meaning, and plausibly it is better to know all of this and act accordingly than not (and this is to say nothing of the possible eschatological implications of believing in and following the will of a perfectly good God; i.e., our ultimate destiny - often but not necessarily conceived of as an eternal residence in heaven or hell - might be affected by our belief in God and our acting in accordance with God's will). Indeed, given the plausible assumption that we would be happier if we think our life has a higher meaning than not, an endorsement of (a) has positive expected utility. If we endorse (a) but (b) is actually true, then we will be living a lie, but plausibly, we will still be better off, from an expected utility standpoint, thinking that our beliefs and actions have a higher meaning even though they do not. Whether (a) is true or not, we gain positive expected utility from believing that it is. Now suppose that we assert (b): the cause of the universe does not take an interest in us, either because it simply doesn't care about us or because it is not even sentient. If we assert (b) and (b) is false, then this seems to have a very negative utility. For example, if our lives have some higher meaning, yet we are not aware of this and do not act accordingly, it seems we lose a great deal (again, if a traditional eschatological policy is embraced, we could lose everything). But if we assert (b) and (b) happens to be true, then we still lose out, because again, it is better to believe that one's life has a higher meaning than not, even if the belief is false. But the main point is that one risks so much - too much - in assuming that the first cause is impersonal because the first cause might be personal. A belief in option (a) has a higher expected utility than a belief in option (b), so assuming that it is rational to maximize expected utility, we should endorse (a). That is, in the absence of strong evidence that says otherwise, we should believe that the cause of the universe is

${ }^{18}$ The disjuncts in (b) amount to the same thing from a practical standpoint, in our opinion, so we treat them together. If the cause of the universe is sentient yet wholly indifferent to us, then so far as we are concerned, the cause might as well be a non-sentient entity. 
a personal being that at least takes an interest in us because it is in our best interest to do so. ${ }^{19}$

At this point, it is clear that at least some of our pragmatic arguments have a strong affinity with another pragmatic argument in philosophy of religion, Pascal's Wager. ${ }^{20}$ Of course, Pascal argues that we should believe in God, even in the absence of a proof of God's existence, because doing so is in our best interest. We have little or nothing to gain by not believing in God, but potentially might lose everything. On the other hand, by believing, we might gain everything. The argument above is very similar. We have little or nothing to gain by denying that the cause of the universe is a personal being. On the other hand, by believing, we might gain everything.

The second question we address is: given that the cause of the universe is sentient and takes an interest in us, is this being all good or all evil? ${ }^{21}$ Again, we have two options: (a) we can assert that the being is good, and so is just, rational, non-deceitful, full of love, or has whatever properties one might consider to be good, or (b) we can assert that it is evil, and so is unjust, irrational or at least non-rational, deceitful, hateful or has whatever properties one might consider to be evil. Suppose we opt incorrectly for (b), i.e., we assert that the being is evil but it is in fact good. This is clearly a negative outcome. For suppose, as certainly seems to be the case, that we would be happier believing that the being that caused the universe - and so us - is good than believing that it is evil. If so, then we lose happiness while believing a falsehood. Furthermore, if we incorrectly opt for (b), then it will be impossible to correctly determine the being's intentions for us. Again, this being takes an interest in us, so it might want us to live a certain way, or might have a higher purpose in mind for us etc. But if we assume that the being is evil, then we could never accurately

\footnotetext{
${ }^{19}$ Again, this argument relies on two very weak claims: (i) it is better (in terms of expected utility) to think that one's life has a higher meaning or higher purpose than not and (ii) it is rational to increase expected utility.

${ }^{20}$ B. Pascal, Pascal's Pensées, translated by W. F. Trotter, 1910.

${ }^{21}$ This issue arises in a different context in W. Morriston, "The Evidential Argument from Goodness," The Southern Journal of Philosophy XLII (2004): 87-101, not to mention in Descartes's Meditations. One might think we have posited a false dichotomy; perhaps God is more good than evil on average or is more evil than good on average? Even if one adds these possibilities though, our argument still works (because our argument can still show that it is rational to believe that God is good on average etc).
} 
discern what it is this being wants us to do if it happens to be good. Now suppose that we assert (b), i.e., we assert that the being is evil, and the being is in fact evil. This option also has negative utility, for a number of reasons. First, the thought that there is an evil being that created the universe and so us is ominous, to say the least; we would be much happier believing that the being is good, even if it isn't. Second, again, this being might have some higher plan for us, it might want us to live a certain way, and so on, but the will of an evil being could never be discerned, or at least could never be discerned with any degree of certainty, because of the likely character traits (i.e., irrationality, deceitfulness, etc.) that an evil being would have. So, we could never determine with any confidence what this being expects from us. Third, even if we could correctly ascertain this being's intentions for us, we hopefully would not wish to fulfill them anyhow; since the being is evil, its intentions for us would likely be evil as well. In short, if we assert that the being is evil, then nothing is gained and much will be lost; whether the being is evil or not, there is negative expected utility to claiming that it is evil. ${ }^{22}$

But if we assert (a), and so claim that the being is good, both outcomes are positive. For if we assert that the being is good and it is good, then we might be able to discern its intentions for us, and we might wish to fulfill them, and the thought that a good being caused the universe is much more pleasant than the thought that the being is evil, and so on. Likewise, if we assert that the being is good yet it is evil, this is still better than thinking that the cause of the universe is evil for various reasons given above. So, given that both outcomes for holding that the cause of

${ }^{22}$ Someone might object that if we assume that the being is evil and it is evil, this gives us certain advantages. For example, perhaps we could somehow get on this being's "good side" by performing immoral acts, like kicking puppies etc. But this is problematic for the reasons given above. If God is evil, God might be irrational, or at least deceitful, unjust etc. If so, there is no reliable way to determine what this God wants from creation. Thus, it is not as if a believer in this deceitful being can gain favor by, for example, performing evil acts. One might get on an evil being's good side this way, but one just as easily might not (for all we know, this evil being might prefer those who go against the wishes of their creator, and so do good etc.). Again, since the being is not even truthful, there is simply no way to figure out what it wants. It could, for example, reward everyone, or it might randomly torture some and reward others, or it might simply torture everyone. Nothing is gained, but much is potentially lost, by claiming that the cause of the universe is evil. 
the universe is evil are negative, while both outcomes for holding that the cause is good are positive, and given that it is rational to increase expected utility, it is rational to assert that the cause is good.

Here is another way to look at our argument. There are four possible scenarios: (i) we assert that God is evil and God is evil, (ii) we assert that God is evil but God is good, (iii) we assert that God is good but God is evil, and (iv) we correctly assert that God is good. The expected utility for (i) is zero at best because there is no reason to assume that an evil being would prefer that people believe in it; again, this being might torture everyone indiscriminately etc. Option (ii) has very low - if any - expected utility because a good God would probably not appreciate being considered evil. It is important to note that a decision to assert that God is evil might yield actual utility; for example, perhaps this being is evil and rewards those who believe in it. However, there is no expected utility to such a decision because there is no reason to expect that an evil God would be "pleased with" someone believing in it, and there is certainly no reason to assume that a good God would be "pleased with" someone who believed God to be evil (we are assuming that God being "pleased with" us would increase positive utility). This is hardly a profound claim: decisions do have unexpected consequences. Even so, it would be absurd to assume that all decisions will have unexpected consequences and decide accordingly. If we were to do this, our decision-making faculties would be worthless. We would not, for example, wager a penny for a million dollars, even if the odds of winning the bet were 99.9\%, because of concerns related to possible unexpected consequences. Option (iii), for reasons expressed above (i.e., an evil God's will is inherently undecipherable), has low expected utility as well; but option (iv) has high expected utility, so high that it makes the expected utility for claiming that God is good greater than the expected utility for claiming that God is evil. So, if we are rational, we should assert that God is good.

\section{OBJECTIONS}

In this section, we consider some possible objections.

One might object, "The pragmatic arguments can only show that it is in our best interest to endorse your premises, and so theism. But this 
does not mean the premises are true." But this objection misconstrues the goal of the pragmatic arguments (and indeed, the goal of pragmatic arguments for theism in general). The pragmatic arguments do not attempt to show that the premises are true; rather, they merely attempt to show that it is rational to endorse them. The claim that theism is rational is still a significant claim; many atheists claim that theism is irrational. ${ }^{23}$

One might also object that it is rational to endorse the premises of the Cosmological argument only in the absence of strong refutations of the premises. If there are such refutations, then this overrides the pragmatic benefits we get from believing that the premises are true, so we should conclude they are false. It might be rational to endorse a claim if it increases expected utility, but if it can be shown that the claim is certainly false, or even most likely false, it would then be irrational to endorse it. But the problem with this objection is that none of the arguments against the premises of the Cosmological argument are conclusive.

For example, it has been claimed that the argument is contradictory. The first premise claims that everything must have a cause. If so, there must be a cause for the first cause, but a first cause cannot have a cause, by definition. Pruss refers to this issue as the "Taxicab Problem," after Schopenhauer's remark that in the Cosmological argument, the Principle of Sufficient Reason is similar to a taxicab that is used to get somewhere, then sent away when no longer needed. ${ }^{24}$ Note, however, that the first premise claims that every contingent entity must have a cause. If one holds that the first cause is necessary, as theists will, there is no contradiction. In other words, since - by design - (1) only applies to contingent beings, one cannot apply it to the existence of a necessary being to ask what its cause is. This is a commonplace response to the Taxicab problem (it is mentioned in Pruss, for example); we bring the issue up only because the objection is so common.

For a different example, some (e.g., Hume) have claimed that premise one is conceivably, and so possibly, false. ${ }^{25}$ We can easily conceive of

${ }^{23}$ On the alleged irrationality of theism, see, e.g., R. Dawkins, The God Delusion (Transworld Publishers, 2006).

${ }^{24}$ See again A. Pruss, "Leibnizian Cosmological Arguments," The Blackwell Companion to Natural Theology, edited by W. L. Craig and J.P. Moreland (Oxford: Blackwell Publishing, 1999).

${ }^{25}$ Again, Hume's most direct attack on the Cosmological argument is in the Dialogues, part IX. 
a contingent entity simply appearing ex nihilo, so the first premise is not necessarily true. The objection is far from conclusive, however; in fact, it seems deeply misguided. The first premise might be true in our world yet false in some logically possible worlds; for instance, perhaps the laws of nature entail (1) in our world, but the laws of nature that hold in our world, or any laws of nature at all, might not hold in some logically possible world, so (1) is false in that world. But (1) need not be necessarily true; it merely needs to be true in our world. Perhaps the argument merely shows that it is rational to think that our universe, at least, must have a first cause ${ }^{26}$ This would still be a theologically interesting result. To rephrase all of this: we can imagine that a claim might be false, yet the claim might still be true in the actual world. We can imagine that George W. Bush was never president, for example; but unfortunately, this doesn't make it so. Even assuming that conceivability entails possibility (and this is of course controversial), conceivability does not entail actuality, but it would have to for the objection to succeed. ${ }^{27}$

For yet another example, one could object that premise (2) might be false. Our universe is certainly a concretely existing entity, but perhaps our universe is not contingent? Perhaps something had to exist, for instance? But this too is inconclusive. First, it is not clear that something had to exist. This point has been debated for centuries. ${ }^{28}$ But more importantly, even if some entity had to exist, this does not mean that our universe had to exist. For example, suppose that someone says that no universe can be empty, so a given universe might contain a single grain of sand, for example. Even assuming that this is correct, this universe is not numerically identical to our universe (by Leibniz's law) (see above). The claim that there has to be something in any given universe does not entail that any given universe is our universe, and so does not entail that our universe had to exist, and so does not entail that (2) is false.

${ }^{26}$ Of course, this first cause will necessarily exist for the theist, but this is consistent with saying that the argument only establishes a first cause in our world.

${ }^{27}$ Spinoza (Book I of The Ethics) claimed that conceivability entails actuality because he collapsed the possible into the actual. Other examples are difficult to find.

${ }^{28}$ See B. Reichenbach, "Cosmological Argument," The Stanford Encyclopedia of Philosophy (Fall 2008 Edition), edited by E. N. Zalta. URL = http://plato.stanford.edu/ archives/ fall2008/entries/cosmological-argument/, 2008. 


\section{CONCLUSION}

We argued that it is rational to accept the premises of the Cosmological argument because endorsing these premises leads to an increase in expected utility; therefore, it is rational to endorse theism. If one thinks that (i) it is rational to increase expected utility, and also (ii) that knowledge is a positive thing, (iii) that we would be happier if the future is open than if it is not, (iv) that if there is a chance that our lives might have some higher purpose, then it is better to know this than not, and (v) that we would be better off assuming that the creator of the universe is good than assuming it is evil, one should conclude that it is rational to endorse theism. ${ }^{29}$

\section{BIBLIOGRAPHY}

Aquinas, T. Summa Theologica. Translated by the Fathers of the English Dominican Province. New York, NY: Benzinger Bros, $13^{\text {th }} \mathrm{C} / 1948$.

Aristotle. The Complete Works of Aristotle, volumes I and II. Edited by J. Barnes. Princeton: Princeton University Press, $4^{\text {th }}$ C BCE/1984.

Clarke, R. Libertarian Accounts of Free Will. Oxford: Oxford University Press, 2003.

Clarke, S. A Demonstration of the Being and Attributes of God And Other Writings. Edited by E. Vailati. Cambridge: Cambridge University Press, 1705/1998.

Craig, W.L. The Kalām Cosmological Argument. London: The Macmillan Press, 1979.

Craig, W.L. The Cosmological Argument from Plato to Leibniz. London: The Macmillan Press, 1980.

Craig, W.L. "In Defense of the Kalām Cosmological Argument." Faith and Philosophy 14.2 (1997): 236-247.

Dawkins, R. The God Delusion. Transworld Publishers, 2006.

Descartes, R. Meditations on First Philosophy in The Philosophical Writings of Descartes, Volume 2. Translated by J. Cottingham, R. Stoothoff, and D. Murdoch. Cambridge: Cambridge University Press, 1641/1984.

Gale, R. and Pruss, A.R. "A New Cosmological Argument." Religious Studies 35 (1999): 461-476.

${ }^{29}$ The authors would like to thank an anonymous referee for extremely helpful comments on an earlier draft. 
Hume, D. Dialogues Concerning Natural Religion. Indianapolis: Hackett, 1779/1980.

Kane, R. The Significance of Free Will. New York: Oxford University Press, 1996.

Kant, I. Critique of Pure Reason. Cambridge: Cambridge University Press, 1980/1998.

Koons, R. "A New Look at the Cosmological Argument." American Philosophical Quarterly 34 (1997): 171-192.

Leibniz, G. The Monadology. Translated by George MacDonald Ross, $1714 / 1999$.

Morriston, W. “The Evidential Argument from Goodness." The Southern Journal of Philosophy XLII (2004): 87-101.

O'Conner, T. "Free Will." The Stanford Encyclopedia of Philosophy (Fall 2008 Edition). Edited by E. N. Zalta, URL = http://plato.stanford.edu/ archives/ fall2008 /entries/freewill/.

Oppy, G. Arguing about Gods. Cambridge: Cambridge University Press, 2006.

Pascal, B. Pascal's Pensées. Translated by W. F. Trotter, 1910.

Plato. The Laws of Plato. Translated by T.L. Pangle. New York : Basic Books, 1980.

Pruss, A. "Leibnizian Cosmological Arguments." The Blackwell Companion to Natural Theology. Edited by W. L. Craig and J.P. Moreland. Oxford: Blackwell Publishing, 1999.

Reichenbach, B. "Cosmological Argument." The Stanford Encyclopedia of Philosophy (Fall 2008 Edition). Edited by E. N. Zalta. URL = http://plato.stanford. edu/archives/ fall2008/entries/cosmological-argument/, 2008.

Rowe, W. The Cosmological Argument. Princeton: Princeton University Press, 1975.

Spinoza, B. The Collected Works of Spinoza Vol. I. Edited and Translated by Edwin Curley. Princeton: Princeton University Press, 1677/1985.

Taylor, R. Metaphysics. Englewood Cliffs: Prentice-Hall, 1992. 